Cristiane Queiroz Barbeiro Lima ${ }^{1}$ Cristiane Maria Galvão Barbosa ${ }^{2}$ Renata Wey Berti Mendes ${ }^{3}$ Cesar Augusto Patta ${ }^{4}$

${ }^{1}$ Fundação Jorge Duprat Figueiredo de Segurança e Medicina do Trabalho (Fundacentro), CTN. São Paulo, SP, Brasil.

${ }^{2}$ Fundação Jorge Duprat Figueiredo de Segurança e Medicina do Trabalho (Fundacentro), Centro Regional da Bahia. Salvador, BA, Brasil.

${ }^{3}$ Programa de Doutorado em Engenharia de Produção da COPPE- Instituto Alberto Luiz Coimbra de Pós-Graduação e Pesquisa de Engenharia/Universidade Federal do Rio de Janeiro. Rio de Janeiro, RJ, Brasil.

${ }^{4}$ Centro de Referência em Saúde do Trabalhador de São Paulo. São Paulo, SP, Brasil.

Contato:

Cristiane Queiroz Barbeiro Lima

E-mail:

cristianequeiroz@fundacentro.gov.br

Trabalho não subvencionado.

Os autores declaram não haver conflitos de interesses.

Recebido: 12/08/2013

Revisado: 21/05/2014

Aprovado: 16/06/2014

\section{Assédio moral e violências no trabalho: caracteri- zação em perícia judicial. Relato de experiência no setor bancário}

\author{
Bullying and violence at work: characterization in a forensic \\ expert analysis. Reporting an experience in the banking sector
}

\section{Resumo}

Este artigo apresenta uma investigação sobre assédio moral em trabalhadores acometidos por Lesões por Esforços Repetitivos/ Doença Osteomuscular Relacionada ao Trabalho (LER/DORT) realizada durante perícia judicial de uma ação coletiva de trabalhadores de uma instituição bancária. Apresenta-se o plano de trabalho de uma perícia envolvendo caracterização de assédio moral e violências no trabalho, destacando-se as dificuldades encontradas, principalmente, pelo tempo decorrido entre a abertura do processo e a perícia, pelo medo sentido pelas testemunhas e pessoas potencialmente envolvidas e pela ausência de instrumentos padronizados para caracterização do assédio. A análise pericial identificou ambiente de trabalho propício ao assédio moral devido aos sistemas de gestão e organizacionais adotados e identificou potencialização de sobrecarga mental e psíquica dos trabalhadores com LER/DORT por sujeição a pressões para que desistissem de comprovar a relação da doença com o trabalho. Por seu caráter coletivo, a perícia abriu possibilidades de se analisar e avaliar situações de trabalho que, isoladamente, teriam pesos menores do que vistos sob o olhar sistêmico e organizacional.

Palavras chaves: assédio moral; saúde mental; saúde do trabalhador; perícia; organização do trabalho.

\begin{abstract}
This paper presents an investigation on bullying among workers affected by Repetitive Strain Injury/Musculoskeletal Disorders (RSI/MSD). The enquiry was held during a forensic analysis of a collective lawsuit proposed by workers of a bank. A forensic assessment workplan addressing the characterization of bullying and violence at work is put forward. The difficulties found are emphasized, particularly those related to the time elapsed between the opening of the lawsuit and the forensic analysis, caused by the witnesses' and other individuals' fear and by the lack of standardized instruments to typify bullying. The forensic analysis has identified the workplace conducive to bullying due to the management and organizational systems adopted and identified mental and psychic overload potentiation of workers with RSI/MSD by being subject to pressures to give up showing the relationship disease-work. Due to its collective characteristic, the forensic investigation led to the possibility of analyzing and assessing work situations that would lose their importance if seen alone as compared with a systemic and organizational view.
\end{abstract}

Keywords: bullying; mental health; workers' health; representative action; work organization. 


\section{Introdução}

Este artigo relata a caracterização de assédio moral em trabalhadores acometidos por Lesões por Esforços Repetitivos/ Doença Osteomuscular Relacionada ao Trabalho - LER/DORT realizada através de uma perícia judicial referente a uma ação coletiva movida em 2005 pelo Ministério Público do Trabalho perante denuncia de trabalhadores de uma instituição bancária.

Além das queixas sobre discriminação e assédio moral havia também acusações a respeito de deficiências da empresa no atendimento às Normas Regulamentadoras do Ministério do Trabalho e Emprego ${ }^{5}$ e na elaboração do Perfil Profissiográfico Previdenciário - $\mathrm{PPP}^{6}$.

As alegações com relação ao assédio moral no banco em questão eram as de que a empresa tinha como padrão de conduta assediar moralmente os trabalhadores que apresentavam sintomas de LER/DORT através da submissão destes a atos de constrangimentos variados, que iam desde o isolamento das vítimas dos demais empregados, o não repasse de tarefas, passando por ofensas relacionadas à doença, transferências sucessivas para evitar promoção e pressionar o trabalhador, até a divulgação de dados médicos sigilosos a fim de expor a intimidade do atingido no ambiente de trabalho. Essas citações estavam baseadas em denúncia do sindicato da categoria que relatou e juntou documentação pertinente à situação de empregados do réu dispensados após a constatação de estarem acometidos por LER/DORT, incluindo depoimentos de alguns trabalhadores. As situações relatadas eram referentes ao período entre 1994 a 2003.

Os trabalhos de perícia foram iniciados em março de 2008, momento de nomeação dos membros de uma equipe de perícia multidisciplinar pelo Juiz do Trabalho responsável pela ação. A equipe multidisciplinar foi formada por uma química, especialista em gestão da segurança e saúde no trabalho, uma psicóloga, especialista em ergonomia e dois médicos do trabalho. Vale ressaltar que a atividade pericial foi acompanhada pela Procuradora e Assistente Técnico do Ministério Público do Trabalho, bem como por Assistentes Técnicos da empresa.

Restringindo-se à análise sobre assédio moral em funcionários acometidos por LER/DORT, este artigo apresenta o relato do trabalho de uma perícia mul- tidisciplinar para a caracterização de violências no trabalho, destacando as dificuldades durante esse processo, mas também as vantagens de se analisar situações de trabalho por um conjunto de parâmetros que isoladamente teriam pesos menores do que vistos sob o olhar sistêmico.

\section{Aspectos conceituais}

São vários os entendimentos sobre a definição de assédio moral no trabalho, também conhecido como violência moral no trabalho (SOBOL, 2006; MACIEL et al., 2007; GUIMARÃES; RIMOLI, 2006; FREITAS; HELOANI; BARRETO, 2008).

Marie-France Hirigoyen, pesquisadora francesa que deu grande divulgação ao tema através de seus livros, define o assédio moral como "qualquer conduta abusiva (gesto, palavra, comportamento, atitude...) que atente, por sua repetição ou sistematização, contra a dignidade ou integridade psíquica ou física de uma pessoa, ameaçando seu emprego ou degradando clima de trabalho" (HIRIGOYEN, 2002, p. 17).

Para Sobol (2006), o assédio moral é uma forma de violência psicológica, uma transgressão às normas de convívio em sociedade, e como consequência restringe ações e comportamentos através do uso de poder de forma abusiva, podendo causar prejuízo no desenvolvimento e danos para a saúde física e emocional da vítima.

Maciel e colegas (2007), embora tenham identificado à ausência de consenso entre as definições do assédio moral no trabalho, dizem que todas apontam para a ocorrência de atos negativos ou situações constrangedoras que perduram por certo período de tempo e frequência e nas quais a vítima se sente intimidada.

Devem ser excluídas da constatação de assédio moral as situações de estresse causado pela premência de tempo na execução de algum trabalho ou devido à competitividade empresarial existente, entendido como exercício de poder diretivo do empregador. Ter um mau dia, manter um conflito com um colega, sofrer por causa de um chefe exigente ou perfeccionista, atritos habituais, tensões e incidentes isolados não devem ser confundidos com situações abusivas e que ferem o moral do trabalhador (GUIMARÃES; RIMOLI, 2006). As agressões pontuais são violências, entretanto, não caracterizam assédio, pois a observação da constância de atos violentos de diversas formas é que os tornam destruidores e que levam ao assédio (HIRIGOYEN, 2002).

\footnotetext{
${ }^{5}$ Os itens referentes às deficiências no atendimento às Normas Regulamentadoras do Ministério do Trabalho e Emprego, especificamente ao gerenciamento dos riscos ergonômicos (NR 17), ao Programa de Controle Médico de Saúde Ocupacional (NR 7), ao Programa de Prevenção de Ricos Ambientais (NR 9) e à descrição dos Perfil Profissiográfico Previdenciário- PPP, não serão abordados neste texto.

${ }^{6}$ Perfil Profissiográfico Previdenciário (PPP) é um documento solicitado pela Previdência Social que deve ser preenchido pela empresa para a comprovação da exposição dos empregados a agentes nocivos, para o conhecimento de todos os ambientes e para o controle da saúde ocupacional de todos os trabalhadores.
} 
A compreensão do assédio moral requer um olhar para o movimento entre a objetividade do trabalho e a subjetividade dos trabalhadores, trazendo a importância de se identificar aspectos da organização do trabalho que se relacionam com a ocorrência do fenômeno (SOBOL, 2006). Esta abordagem acrescenta mais um enfoque: o reconhecimento do assédio organizacional como contribuinte e propiciador de situações de assédio moral no ambiente de trabalho.

O assédio organizacional é um processo no qual a violência está inserida nos aparatos, nas estruturas e nas políticas organizacionais ou gerenciais, que são abusivas e inadequadas. Visa produtividade e controle organizacional. O objetivo do assédio organizacional não é atingir uma pessoa em especial, mas sim controlar todo o grupo indiscriminadamente (SOBOL, 2008). É considerado um problema organizacional por ocorrer no ambiente de trabalho, entre pessoas que são parte da estrutura organizacional, que detêm prerrogativas a partir de papéis organizacionais e encontram respaldo em questões ou aspirações organizacionais (FREITAS; HELOANI; BARRETO, 2008).

A sociedade moderna tem se estruturado fortemente sobre o aspecto econômico e o processo de trabalho tem sido seu maior representante. As novas formas de gestão e organização do trabalho estão pautadas pela produtividade, competitividade, cumprimento de metas em curto prazo, desempenhos sempre mais elevados, incorporação tecnológica e atualização permanentes. Na medida em que a organização do trabalho se fundamenta no aspecto econômico, quebram-se as relações e contratos de trabalho, legitima-se a competição em todos os níveis, individualizam-se as culpas e os prejuízos pelo não atendimento de metas, eleva-se o ritmo do trabalho e coloca-se a guerra econômica como álibi para justificar a sobrevivência da empresa a qualquer custo gerando ambiente de trabalho em que ocorre e permanece a violência (FREITAS; HELOANI; BARRETO, 2008).

\section{Método}

O trabalho de perícia se desenvolveu em 15 meses, a partir de março de 2008.

Inicialmente foi feito um levantamento do suporte teórico por meio de uma revisão da literatura para subsidiar a abordagem do tema e a coleta de dados.
De posse do embasamento teórico-conceitual, foram estabelecidos os procedimentos para análise das alegações apresentadas e os parâmetros/indicadores a serem utilizados.

As informações foram obtidas por meio de documentos, de observações nos locais de trabalho inspecionados e de entrevistas. Os documentos analisados foram: o programa de produtividade e desempenho da empresa desenvolvido em 2009; as orientações sobre a ética corporativa da empresa datada de 2008; o programa de reabilitação ao trabalho e reabilitação profissional de 2007; as listas de trabalhadores aposentados por invalidez /licença ocupacional e tratamentos de saúde dos anos de 2004, 2007 e 2008; as listas de trabalhadores demitidos no ano de 2007; e 19 sentenças trabalhistas envolvendo trabalhadores do banco com doença ocupacional.

Foram realizadas quatro visitas de inspeção em locais de trabalho da empresa em São Paulo (duas agências bancárias, um setor de teleatendimento e um setor de compensação de cheques). Estes locais foram selecionados entre os indicados na ação trabalhista.

As entrevistas foram realizadas com dois trabalhadores em reabilitação selecionados pela empresa, com cinco componentes da equipe de saúde ocupacional, onze representantes da empresa com cargos de supervisão e gerência, três representantes sindicais da categoria bancária e com dez trabalhadores entre afastados e em reabilitação nos locais de trabalho visitados. A escolha entre os trabalhadores afastados foi a partir da identificação de trabalhadores que constavam nas listas de licença ocupacional/tratamento de saúde e também na lista de demitidos. Houve também uma escolha aleatória entre os que constavam na lista de trabalhadores em licença ocupacional/tratamento de saúde de 2008. Considerando a natureza da análise, as entrevistas com cinco trabalhadores afastados foram feitas de forma confidencial, ou seja, sem a presença dos assistentes técnicos das partes, conforme deferimento do Juiz ${ }^{7}$, muito embora, três destes trabalhadores tenham permitido sua identificação no processo judicial.

Os sete depoentes constantes da Ação Civil Pública de 2005 foram também procurados pela equipe pericial, mas apenas dois foram localizados em 2008 e apenas um deles aceitou falar a respeito.

As entrevistas com os trabalhadores seguiram um roteiro com as seguintes questões:

\footnotetext{
${ }^{7}$ De modo geral, em perícias judiciais os assistentes técnicos das partes são comunicados previamente pelo perito do juiz sobre todas as etapas do trabalho a ser realizado, para que, em havendo interesse, participem das mesmas. Para que uma etapa seja feita de forma confidencial há necessidade de deferimento do juiz.
} 
1- Como e quando ocorreu seu processo/desenvolvimento de adoecimento no trabalho?

2- Como a empresa acompanhou ou acompanha seu caso?

3- Como você sente que foi tratado pela empresa quando do seu adoecimento?

4- Quais as consequências desse processo para você?

5- Em que situação você se encontra hoje, quanto à renda mensal, benefício do INSS, saúde física e mental?

Os nomes das chefias e dos médicos do trabalho, embora tenham sido citados pelos entrevistados, foram apagados, porque o foco da análise foi no desempenho dos serviços da empresa nas circunstâncias analisadas e não em pessoas específicas.

\section{Estabelecimento de indicadores}

Para se proceder à análise das informações coletadas com vistas ao assédio moral, optou-se por agrupá-las segundo temas (organização e gestão do trabalho geral e relações interpessoais e subjetividade), que por sua vez, incluíam aspectos específicos, denominados de indicadores. Estes foram definidos com base na análise das referencias bibliográficas levantadas para o embasamento teórico conceitual.

\section{a) Aspectos relacionados à organização e gestão do trabalho}

A organização do trabalho é constituída por elementos prescritos que expressam as práticas de gestão de pessoas e do trabalho presentes no processo produtivo e balizam o seu funcionamento (FERREIRA; MENDES, 2003 apud FERREIRA et al., 2006).

Como indicadores da organização e gestão do trabalho foram utilizados:

\section{Indicadores gerais}

- Programa de produtividade e estabelecimento de metas.

(hierarquia de cobrança de metas/ participação dos trabalhadores/ abusos, quadro comparativo).

- Sistemas de recompensas e punições. (prêmios, incentivos individualizados, advertências, promoção sem levar em conta capacitação, mas somente o resultado de vendas).

- Sistema de avaliação de desempenho (somente por resultados/ acessibilidade hierárquica / capacitação)
- Sistemas de motivação (ambiente de trabalho enfeitado, comemorações, ranking)

- Rotatividade e critérios de transferências.

Indicadores diretamente relacionados aos portadores de $L E R / D O R T$

- Procedimentos associados à emissão de CAT Comunicação de Acidentes do Trabalho e recorrências.

- Procedimentos referentes ao encaminhamento/ acompanhamento dos funcionários junto ao INSS- Instituto Nacional do Seguro Social.

- Demissões, em particular das pessoas portadoras de doença ocupacional. Procedimentos de reabilitação.

b) Aspectos referentes às relações interpessoais e subjetividade

Para os parâmetros das relações interpessoais e subjetividade, analisamos e investigamos os aspectos que correspondem ao assédio moral que envolve a pessoalidade, a exclusão, situações onde se pode prejudicar subjugar e anular. Para atos e fatos que caracterizam o assédio moral tomou-se como referência à lista de atos hostis de Hirigoyen (2002) categorizadas da seguinte forma:

- Deterioração proposital das condições de trabalho;

- Isolamento e recusa da comunicação/discriminação;

- Atentado contra a dignidade;

- Violência verbal, física e sexual.

Para análise dos indicadores relacionados à organização e gestão do trabalho se utilizou as observações nos locais de trabalho, os documentos e registros solicitados durante as visitas e as entrevistas com representantes da empresa e trabalhadores. A estratégia utilizada desenvolveu-se de modo a considerar os aspectos objetivos (organizacionais) e subjetivos (inter-relacionais, pessoais) do fenômeno a ser investigado, separando, o quanto possível, uns dos outros.

As conclusões vieram da apresentação documental, das semelhanças entre fatos e situações colocadas pelos entrevistados, incluindo os depoimentos constantes da abertura deste processo, assim como de análises do conjunto de indicadores encontrados. 


\section{Resultados}

Quanto aos aspectos relacionados à organização e gestão do trabalho

\section{Indicadores gerais}

Programa de produtividade e estabelecimento de metas

A produtividade e as metas diferiam conforme o departamento e a função ou de acordo com o trabalhador. Ficava a cargo dos gestores a escolha dos métodos e técnicas para administrar o alcance das metas estabelecidas. Para algumas funções ou departamentos o coletivo era avaliado e essa avaliação era de responsabilidade da chefia local, enquanto que em outras, a administração do alcance das metas era individual, ou seja, cada um era responsável por atingir sua meta. As recompensas chegavam a acrescentar na remuneração, em média 30\% sobre a remuneração mensal do trabalhador podendo chegar a 50\%, conforme esclarecimentos e planilhas de horas extras/plantões realizados em determinado setor da empresa.

Já nas agências, o operador de caixa tinha a tarefa de prestar atendimento com pressão do tempo de atendimento, que era medido pelo tempo que o público permanece na fila, não podendo ultrapassar 25 minutos. Era exigido ainda desse operador vender serviços, tais como planos de capitalização, seguros e débitos automáticos, pelos quais recebia pontuação individual, que era administrada pelo chefe.

\section{Sistema de avaliação de desempenho}

O sistema de avaliação de desempenho era prescrito tendo como objetivo principal o máximo aproveitamento da força de trabalho por meio de sucessivas avaliações. Era um sistema de avaliação de resultados do trabalho individual e de controle do comportamento. Estava dirigido para verificação do cumprimento da tarefa, de acordo com o prescrito pela organização, e para percepção de insatisfações e de oportunidades de melhorias no processo de trabalho.

Os documentos desse sistema indicavam e estabeleciam ações e reações que a empresa desejava que o funcionário exercesse: constantes adaptações aos conflitos das relações de trabalho; a busca pelos resultados estabelecidos no programa de incentivo à produção, preocupação em segurar o cliente; e a constante capacitação técnica para atender às exigências do trabalho.

As avaliações de desempenho eram individuais e podiam ser realizadas em diversas periodicidades: diárias, semanais, mensais e até anuais. A avaliação semanal, por exemplo, dizia respeito ao quanto o trabalhador alcançava em relação às metas de produção prevista para a semana. Para os trabalhadores do setor de teleatendimento este programa também levava em consideração o cumprimento das pausas programadas. Esta avaliação era feita pelo chefe considerando o esforço do trabalhador na adesão às campanhas semanais.

Na agência bancária ocorriam reuniões diárias, denominadas de "dar e receber feedbacks" e havia um instrumento, no qual diariamente os trabalhadores manifestavam críticas e elogios aos colegas, a si mesmos e aos gestores, que eram expostos em quadro, no local de trabalho.

\section{Sistema de motivação}

O sistema de motivação do banco estabelecia constantemente prêmios e reconhecimentos individuais, inclusive com pódium (cartaz com pedestais de primeira, segunda e terceira posição com fotos e caricaturas de funcionários) exposto no ambiente de trabalho.

Outra característica desse sistema, observada durante perícia num setor de teleatendimento, era a manutenção de ambiente constantemente enfeitado de acordo com temas sazonais (natal, carnaval, páscoa, halloween etc), sendo que existia uma verba própria de cada gerência/setor para isto.

$\mathrm{Na}$ agência bancária eram realizadas reuniões mensais onde eram selecionados os atendimentos exemplares, havendo um incentivo para que o trabalhador se inscrevesse para concorrer.

\section{Rotatividade e critérios de transferência}

Outro indicador de assédio organizacional que se apresenta importante na análise foi observado no setor de teleatendimento, no qual ocorriam de uma a duas demissões ao mês e de sete a oito transferências mensais, conforme informações obtidas durante visita pericial realizada. Na ocasião da perícia este setor estava com 424 funcionários e 2,36\% de rotatividade ao mês.

\section{Indicadores diretamente relacionados aos portadores de LER/DORT}

\section{Emissão de CAT- Comunicação de Acidentes do Trabalho}

A empresa emitia CAT somente nos casos confirmados de doença ocupacional e, segundo o médico do trabalho na ocasião, a empresa "não faz controle preciso das CAT emitidas pela empresa, pelo sindicato ou com base no Nexo Técnico Previdenciário porque a atuação é em cima de todos os tipos de afastamento e até em quem não se afastou”.

A lista de afastamentos do trabalho emitida pelo serviço médico da empresa, referente ao ano de 2008, 
indica que, do total de 642 afastamentos devido a doenças do sistema osteomusculares, $55 \%$ foram classificados como auxilio doença acidentário (B 91) ${ }^{8}$ e 45\%

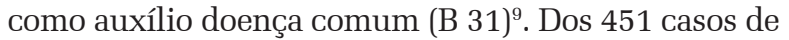
afastamentos devido a transtornos mentais, $27 \%$ foram classificados como auxílio doença acidentários (B 91) e 73\% classificados como auxílio doença comuns (B 31).

\section{Encaminhamento/acompanhamento dos funcionários junto ao INSS.}

Os trabalhadores entrevistados referiram problemas gerenciais relacionados à marcação de perícias e pagamentos de benefícios. Conforme esclarecimentos da equipe de saúde ocupacional e entrevistados, às vezes a empresa encaminhava pelo seu setor de benefícios ou os trabalhadores iam diretamente para o INSS, não existindo um procedimento padrão para encaminhamento.

Por exemplo, um funcionário afastado por transtorno mental e LER/DORT, havia perdido uma pericia e há dois meses estava ligando para a empresa para remarcar. Até o momento que finalizamos essa entrevista não havia recebido o retorno da empresa e estava preocupado com os descontos salariais que vinham acontecendo desde então.

Há um procedimento feito pelo banco, previsto em Convenção Coletiva nos casos de afastamento para benefício pelo INSS, de ser concedido adiantamento pela empresa, até que o trabalhador passe efetivamente a receber do INSS, a partir daí sendo feitos descontos parcelados. Este procedimento não era claramente compreendido e esclarecido, causando problemas no planejamento orçamentário dos trabalhadores, segundo dois dos entrevistados.

\section{Procedimentos para reabilitação}

Segundo a equipe de saúde ocupacional da empresa, uma parcela de funcionários afastados por LER/DORT quando recebia alta de benefício previdenciário, era reconduzido ao banco com restrições impostas pelo INSS, em geral, referentes à cobrança de metas e realização de horas extras/plantões. Nestes casos, preferencialmente o banco readaptava o trabalhador no mesmo local/ambiente em que ele trabalhava antes do afastamento. Sendo assim neste ambiente organizacional passavam a conviver trabalhadores que aparentemente tinham a mesma condição de trabalho, porém que apresentavam realidades contraditórias, uns com as restrições impostas e outros não. Esta situação gerava, para alguns funcionários em readaptação ou considerados readaptados, constrangimentos frente aos outros colegas, muitas vezes fazendo com que eles ultrapassassem os limites impostos pelas restrições para diminuírem a diferença diante dos outros trabalhadores, conforme relato obtido durante entrevista pericial.

Outra situação identificada foi que o sindicato em entrevista com a equipe pericial havia informado que a empresa, nos casos em que o trabalhador solicitava recurso junto ao INSS para continuação de beneficio, solicitava que fizessem uma declaração em documento no qual o funcionário assumisse sua incapacidade de retorno ao trabalho, isentando a empresa sobre os encargos trabalhistas durante o período de avaliação dos recursos no INSS. Representes do departamento jurídico da empresa inicialmente negaram haver procedimentos formais para esses casos, porém, em reunião posteriormente realizada com a equipe pericial, na presença da Procuradoria do Trabalho, do sindicato e da empresa,, tal documento foi apresentado pelo sindicato e então reconhecido pelos prepostos da empresa presentes.

Os entrevistados da equipe de saúde ocupacional da empresa reconheceram que tinham dificuldades em acompanhar todos os casos de trabalhadores em reabilitação e afastamento, apesar de esforços neste sentido.

\section{Demissão de trabalhador com doença ocupacional}

Em análise a uma amostra de processos contra o banco em questão, constantes no Sistema de Informações Trabalhista - Sentenças, Comarca de São Paulo, coletados pela Procuradoria Regional do Trabalho entre 2002 a 2008, encontramos 19 casos de dispensas de trabalhadores com doenças relacionadas ao trabalho, reconhecidos ou não pela empresa, em especial do tipo LER/DORT, incluindo casos em período de estabilidade.

\section{Quanto aos aspectos referentes às relações interpesso- ais e subjetividade}

Para análise das relações interpessoais e de subjetividade foi considerada a semelhança de situações e relatos, bem como a coerência na descrição das histórias ao invés de testemunhas. Destacam-se dois depoimentos que referiram atitudes hostis em relação ao trabalhador portador de LER/DORT, por meio de ações de discriminação, atentado contra a dignidade e violência verbal, apesar de estarem em uma situação prescrita de "proteção" pela restrição de cobranças de metas diretamente da chefia.

\footnotetext{
${ }^{8}$ B91 é o código de beneficio previdenciário que de acordo com o estabelecido no Decreto 6.042/2007 identifica o afastamento do trabalho devido à doença relacionada ao trabalho.

${ }^{9}$ B31 é o código de beneficio previdenciário que de acordo com o estabelecido no Decreto 6.042/2007 identifica o afastamento por doença considerada comum.
} 
O depoente "A" relatou que quando voltou a trabalhar com restrições devido ao problema de LER/ DORT, após seu primeiro afastamento, no setor de teleatendimento, havia outros trabalhadores que também apresentavam doença relacionada ao trabalho e que o supervisor do setor fazia reuniões coletivas e individuais com estes trabalhadores e costumava chamá-los de "lesados do trabalho", um sarcasmo em relação à condição deles.

Nos vários retornos ao trabalho conta ter ouvido dos supervisores de bankfone/teleatendimento as seguintes frases: "Você está atrapalhando o meu plano de metas!", "Você devia sair de licença logo", "Por que você não pede demissão? Vai ser melhor para vocêe!" (Esta frase foi relatada por mais de um entrevistado).

No último retorno ao trabalho, após afastamento por LER/DORT em 2006, relatou ter ouvido do médico do trabalho da empresa, de forma irônica: "Os afastados voltam a trabalhar por 15 dias e se afastam, só para receber os tickets de alimentação.", "Eu não vou trocar você de área porque você é um funcionário problema! Quem vai te querer?”.

Em decorrência desses episódios, o depoente "A" relatou que se afastou por depressão, mas foi considerado pela empresa como B 31, auxílio doença comum, e, em seguida, foi demitido da empresa por justa causa em maio de 2007. Este funcionário foi reintegrado pela justiça nesse mesmo ano. Quando da entrevista pericial, encontrava-se aguardando reconsideração de alta junto ao INSS, sem estar trabalhando. Informa fazer uso de medicamentos para tendinite e depressão.

O depoente "B" relatou que, após o diagnóstico de doença ocupacional em 1995 e sucessivos afastamentos, passou a ser tratado de forma diferente no trabalho. Segundo o mesmo, os novos trabalhadores, quando em treinamento, não podiam acompanhar os trabalhadores com LER/DORT, pois as chefias os consideravam "maus exemplos" para os novos, relatando ter ouvido do seu supervisor: "Você não acha melhor pedir demissão? Nós te damos um ano de convênio médico!"

Ele relatou ainda que sentia dificuldades nas marcações das perícias pelo banco e passou a administrar diretamente sua relação com o INSS por considerar "menos penoso ser humilhado pelo INSS do que pelo banco."

Estava afastado, com cirurgia marcada quando recebeu uma carta de demissão por justa causa, em maio de 2007. Ganhou na justiça a reintegração imediata ao trabalho em julho de 2007, foi reintegrado e na época da entrevista se encontrava em benefício junto ao INSS. Informou fazer uso de me- dicamentos para tendinites, depressão e "calmantes para dormir". Passou por sete cirurgias relacionadas a LER/DORT.

\section{Quanto ao denunciante constante da Ação Civil Pública, de 2005.}

O único denunciante que concordou em ser entrevistado relatou ter sido perseguido por sua chefia por motivos que considerava pessoais, vindo a desenvolver distúrbios mentais. Conta também que teve doença osteomuscular (DORT), passando por duas cirurgias de punho direito e que apresenta limitações da função da mão direita, não tendo sido reconhecido como doença do trabalho e, portanto, não notificado com CAT. O trabalhador processou a empresa por assédio moral e dizia ter perdido a ação por não conseguir testemunhas.

\section{Discussão}

O primeiro desafio deste trabalho foi o tempo transcorrido entre os eventos, a abertura do processo e o início da perícia judicial. As situações relatadas no processo eram referentes ao período entre 1994 a 2003 e os trabalhos da perícia iniciaram em março de 2008. O fato da solicitação de perícia ter chegado depois de pelo menos cinco anos após as denúncias dificultou a constatação das situações exatamente como apresentadas pelos denunciantes, bem como entrar em contato com os envolvidos nas alegações que instrumentaram o processo.

Diante disto, buscamos a identificação de novos depoentes, com análise de semelhança nas situações vividas pelos trabalhadores, além de um olhar conjunto e multidisciplinar da equipe pericial na organização e gestão do trabalho.

A atividade bancária por volta dos anos 90 passou por várias mudanças de tecnologia, organização e gestão do trabalho. Essas mudanças vieram acompanhadas de aumento no número de registros de LER/DORT e aparecimento de doenças mentais relacionadas ao trabalho (MERLO; BARBARINI, 2002; MACIEL; CAVALCANTE, 2007; LARANJEIRA, 1997). A partir daí as instituições bancárias passaram a agir de modo diferenciado para intervir nesses agravos, alterando por vezes procedimentos de gestão do trabalho e da saúde.

Um fator de relevância encontrado na investigação direta com os trabalhadores foi o medo. As pessoas têm medo de falar de violências que viram, ouviram ou viveram. Foi colocado por eles o medo que tinham de fazer declarações e serem retaliados pela empresa. O ideário é o de que a empresa é podero- 
sa e tudo que for testemunhado pode comprometer a situação atual de quem fala pela possibilidade de influência da empresa tanto no mercado de trabalho quanto nos órgãos públicos. Esse fator foi percebido como limitante para se coletar dados em entrevistas. O papel das testemunhas no assédio moral tem sido abordado por muitos autores (SOBOL, 2006, 2008; GOSDAL; SOBOL, 2009; SOARES, 2011). Em geral, para se proteger cada um tenta se salvar silenciando-se e não ousando denunciar nem ajudar a vítima. Considera-se também que quanto maior o grupo, menor a chance de que as testemunhas intervenham. É a chamada "difusão das responsabilidades". Não se intervêm, pois se acredita que outra pessoa o fará e também por medo de que a violência retorne sobre si (SOARES, 2011).

A análise pericial identificou uma gestão controladora, focada na submissão de comportamentos; na exigência constante de produtividade, principalmente por meio de várias avaliações de desempenho individuais e coletivas, incluindo avaliações de sentimentos, com exposição de rankings no cumprimento de metas; e com processos de não emissão de CAT e demissão de trabalhadores afastados por doença ocupacional, com comprovação na justiça. A avaliação em conjunto dos fatores observados apontam para a potencialização de sobrecarga mental e psíquica a todos os trabalhadores, de diversos grupos da empresa, inclusive trabalhadores com LER/ DORT em reabilitação. Estes últimos sofriam pela situação em particular e por conviverem com pressões comuns a todo grupo de trabalho.

No programa de produtividade do banco analisado, o chefe imediato ficava responsável pela escolha do método de gerir as metas, dando a impressão de alguma autonomia. Se tudo desse certo, todos ganhavam, mas se as metas não fossem atingidas, ele era diretamente responsabilizado e responderia por isso, ou faria com que alguém respondesse, possibilitando situações de assédio moral.

Os relatos que contaram como as vítimas de assédio moral são tratadas por supervisores ou chefias denunciam um caráter de perversão moral (Freitas, 2001) que ocorre pelo ambiente competitivo "Você está atrapalhando o meu plano de metas!", a preocupação passa a ser atingir as metas, e o agressor, então humilha sem sentir culpa, pois seu comportamento agressivo é legitimado pela organização competitiva na qual só o mais forte sobrevive.

Dentre os vários instrumentos de avaliação de desempenho, um deles denominado "dar e receber feedback", contido em material informativo da empresa para os trabalhadores, orienta que o funcionário deve "ouvir sem discutir, não ficar na defensiva, entender o que deve se adaptar, aceitar o que deve ser adaptado sob o ponto de vista do gestor e ainda agradecer e pedir mais avaliações”. Estas orientações refletem o doutrinamento do comportamento subalterno, mesmo perante a possibilidade de que exista o processo de avaliação "feedback" de funcionários para um gestores. De acordo com os conceitos da psicodinâmica do trabalho (DEJOURS, 1992, 2004; DEJOURS et al., 1994) há um distanciamento entre o que se prescreve e o que realmente é sentido e pode acontecer. O poder de decidir sobre a empregabilidade de alguém está, em princípio, com a hierarquia superior que exerce o controle comportamental sobre o ser imediatamente de nível inferior (BRITTO, 2001). Qualquer sistema de avaliação que não considere essa realidade é falho. Os recursos de gestão adotados pela empresa focam fortemente o controle do comportamento individual, na competição e na comissão e prêmios (desde cestas de cosméticos, eletrodomésticos, até viagens) para atingir as metas preconcebidas pela hierarquia, não privilegiando discussões para eliminação de dificuldades estruturais e de níveis de poder.

O sistema de motivação estimula a comparação de desempenho e a competição entre os trabalhadores, seja pelo ranking de produtividade explícito no setor de teleatendimento, ou pelas agências bancárias com a aplicação do programa "atendimento exemplar". Essa prática se caracteriza como "gestão por estresse", uma das expressões do assédio moral organizacional, que tem como objetivo melhorar o desempenho e a eficiência no trabalho sem pretensão de destruir o trabalhador, embora as consequências na saúde possam ser desastrosas pelos exageros da pressão imposta (SOBOL, 2006, 2008; GOSDAL; SOBOL, 2009).

Este tipo de ambiente de trabalho é altamente propício ao assédio moral. É preciso compreender que estas novas formas de organização não conduzem necessariamente ao assédio moral, mas tornam seu terreno fértil (SOARES, 2002). Mesmo que esses procedimentos não tenham em vista especificamente alguém especial, aproxima-se do assédio moral uma vez que a intenção é colocar os indivíduos sob domínio a fim de submetê-los (HIRIGOYEN, 2002).

Em relação aos demais indicadores analisados, foi encontrado que a rotatividade, para o setor de teleatendimento do banco foi de $2,36 \%$ ao mês, superior ao encontrado no estudo de Vilela e Assunção (2004) que considerou ser expressiva a rotatividade do setor, com resultados em torno de $2 \%$ ao mês, o que, segundo os autores, ao término de dois anos se tem a substituição de quase todo o efetivo.

Na questão de emissão de CAT, se constatou por meio dos relatos, uma situação constrangedora e de assédio, pois foi relatado que a todo o momento o 
trabalhador está sendo questionado e duvidado em relação à doença e sua origem, havendo pressão para que o trabalhador desista de querer provar que sua doença está relacionada ao trabalho. Os trabalhadores vivem essas situações com grande desconforto emocional pela percepção de que todos acreditam que ele tenha somente interesse em garantir estabilidade no emprego.

Nos encaminhamentos e acompanhamentos dos afastados por doenças ocupacionais, as dificuldades e deficiências relatadas geraram constrangimentos, possibilitando situações de assédio moral, nos casos verificados. A sensação de humilhação é referida pelos entrevistados em relação aos serviços do INSS e da empresa, durante os processos de encaminhamentos dos benefícios, perícias, afastamentos e nos retornos às atividades de trabalho.

No programa de reabilitação profissional da empresa, nos chamou a atenção o fato do foco do programa dar pouca relevância sobre a origem do adoecimento, se ocupacional ou não. A não análise e compreensão da origem do adoecimento dificultam a correção das situações relacionadas ao trabalho, embora tenha sido verificada prescrição de restrições voltadas ao trabalho, em especial ao atendimento de metas.

O assédio moral no trabalho em pessoas adoecidas, menos produtivas, pode ocorrer devido à reabilitação inadequada, o que pode inclusive promover o assédio grupal com a participação de colegas que se sentem sobrecarregados por haver um colega que produz menos por ser um reabilitado (SELIGMAN-SILVA, 2011).

\section{Considerações finais}

O tema assédio moral no trabalho tem sido amplamente discutido tanto no campo acadêmico e científico como na sociedade em geral e vários dos seus aspectos têm sido revelados por meio de estudos, pesquisas cientificas e apresentação de situações.

Uma ação coletiva de trabalhadores de uma mesma empresa, em geral, reflete um descontentamento em relação ao o modelo de gestão aplicado, ao modo de conduzir os problemas organizacionais e suas consequências no trabalho e na saúde. A análise da situação em questão passou pela compreensão de princípios adotados que regem ações e reações comuns a todos os envolvidos no contexto.

Os resultados encontrados permitiram considerar que na instituição bancária analisada ocorreram situações compatíveis com assédio moral e que o ambiente de trabalho é propício a ocorrências de assédio moral devido aos sistemas de gestão e organizacionais adotados.

Este trabalho foi uma experiência ímpar, pois a equipe constituída foi multidisciplinar, possibilitando observar a atividade e o local de trabalho e, ainda, analisar os documentos em grupo, através de olhares distintos, mas complementares. A análise foi sistêmica, considerando dados objetivos, importante para a finalidade pericial e, ao mesmo tempo, não se furtou avaliar e apresentar aspectos subjetivos, fundamentais para a compreensão do processo de assédio moral como um todo.

\section{Contribuições de autoria}

Todos os autores contribuíram igualmente para a elaboração deste trabalho.

\section{Referências}

BRITTO, V. G. P. et al. Relações do poder, conhecimento e gestão de desempenho. Revista de Administração Pública, Rio de Janeiro, v. 35, n. 4, p. 45-62, 2001.

DEJOURS, C. Subjetividade, trabalho e ação. Revista Produção, São Paulo, v. 14, n. 3, p. 27-34, 2004.

DEJOURS, C.; ABDOUCHELI, E.; JAYNET, C. Psicodinâmica do trabalho. São Paulo: Atlas, 1994.

FERREIRA, J. B. et al. Situações de assédio moral a trabalhadores anistiados políticos de uma empresa pública. Psicologia em Revista, Belo Horizonte, v. 12, n. 20, p. 215-234, 2006.
FREITAS, M. E. Assédio moral e assédio sexual: faces do poder perverso nas organizações. Revista de Administração de Empresas, São Paulo, v. 41, n. 2, p. 8-19, abr/jun. 2001.

FREITAS, M. E; HELOANI, J. R.; BARRETO, M. Assédio moral no trabalho. São Paulo: Cengace Learning, 2008.

GUIMARAES, L. A. M; RIMOLI, A. O. Mobbing (Assédio Psicológico) no Trabalho: uma síndrome psicossocial multidimensional. Psicologia Teoria e Pesquisa, Brasília, v. 22, n. 2, p. 183-192, maio/ago. 2006.

GOSDAL, T.; SOBOL, L.A.P. Assédio moral interpessoal e organizacional. São Paulo: LTr. 2009. 
HIRIGOYEN, M. F. Mal estar no trabalho: redefinindo o assédio moral. Rio de Janeiro: Bertrand Brasil, 2002.

LARANJEIRA, S. M. G. Reestruturação produtiva do setor bancário. A realidade dos anos 90. Educação e Sociedade, Campinas, v. 18, n. 61, p. 110-138, 1997.

MACIEL, R. H. et al. Auto relato de situações constrangedoras no trabalho e assédio moral nos bancários: uma fotografia. Psicologia \& Sociedade, Belo Horizonte, v. 19, n. 3, p. 117-128, sept./dec. 2007.

MERLO, A. R. C.; BARBARINI, N. Reestruturação produtiva no setor bancário brasileiro e sofrimento dos caixas executivos. Um estudo de caso. Psicologia $\mathcal{\sigma}$ Sociedade, Belo Horizonte, v. 14 n. 1, p. 103-122, 2002.

RIGOTO, R. M.; MACIEL, R. H.; BORSOI, I. C. F. Produtividade, pressão e humilhação no trabalho: os trabalhadores e as novas fábricas de calçados no Ceará. Revista brasileira de Saúde Ocupacional, São Paulo, v. 35, n. 122, p. 217-228, 2010.

SELIGMANN-SILVA, E. O assédio moral no trabalho. In: SEMINÁRIO COMPREENDENDO O ASSÉDIO MORAL NO TRABALHO. 2010. Anais... São Paulo: Fundacentro, 2013. p. 49-55.
SOARES, A. Assédio moral: o estresse das vítimas e das testemunhas. In: SEMINÁRIO COMPREENDENDO O ASSÉDIO MORAL NO TRABALHO. 2010. Anais... São Paulo: Fundacentro, 2013. p. 35-41.

. Quand le travail devient indécent: le harcèlement psychologique au travail. Montreal: CSQ, 2002. Disponível em:

< http://www.fppe.qc.ca/csst/doc/harcelem.pdf $>$. Acesso em: 15 jun. 2014.

SOBOL, L. A. P. Violência psicológica e assédio moral no trabalho bancário. 2006. 230f. Tese (Doutorado em Ciências)-Faculdade de Medicina, Universidade de São Paulo, São Paulo, 2006.

. Assédio moral/organizacional: uma análise da organização do trabalho. São Paulo: Casa do Psicólogo, 2008.

VILELA, L. V. O.; ASSUNÇÃO, A. A. Os mecanismos de controle da atividade no setor de teleatendimento e as queixas de cansaço e esgotamento dos trabalhadores. Cadernos de Saúde Pública, Rio de Janeiro, v. 20, n. 4, p. 1069-1078, jul./ago., 2004. 